\title{
Thyroid carcinoma metastatic to the globe
}

\author{
THOMAS L. SLAMOVITS, ${ }^{1}$ JAMES P. MONDZELEWSKI, ${ }^{1}$ AND \\ JOHN S. KENNERDELL, ${ }^{2}$ \\ From the ${ }^{1}$ Department of Ophthalmology, University of Pittsburgh, and the ${ }^{2}$ Departments of Ophthalmology \\ and Neurology, University of Pittsburgh, USA
}

SUMMARY We report a case of thyroid carcinoma metastatic to the globe. In our survey we found thyroid carcinomas to metastasise to the eye rarely. In addition, we found metastases from the thyroid to be more common to the orbit than to the globe-a reverse of the pattern noted with tumours in general.

Recently we had the opportunity to evaluate a patient in whom we found a metastatic lesion in the globe from a primary thyroid carcinoma. This led us to review the literature for a survey of the incidence of metastatic thyroid carcinoma to the globe. We found such metastasis to the globe distinctly rare.

\section{Case report}

A 57-year-old black woman was diagnosed as having follicular carcinoma of the thyroid in 1969. The tumour was apparently totally excised at that time. The patient had been previously healthy except for the onset of a left Bell's palsy in 1967 and a long history of neurosensory hearing loss. After the excision of her thyroid carcinoma the patient was maintained on L-triiodothyronine, $50 \mathrm{mg}$ 4 times a day. In June 1973 a nodule was noted in the right paratracheal area which was subsequently shown to be positive for ${ }^{131}$ I uptake. A therapeutic dose of $150 \mathrm{mCi}$ of ${ }^{131} \mathrm{I}$ was administered at that time and L-triiodothyronine was again reinstituted. In May 1974, the patient was found to have a left paratracheal lesion positive for ${ }^{131} \mathrm{I}$ uptake, which subsequent biopsy showed to be metastatic follicular carcinoma of the thyroid. The patient again received $150 \mathrm{mCi}$ of ${ }^{131} \mathrm{I}$.

In November 1974 the patient reported the onset of radicular pain in her lumbosacral area. ${ }^{131}$ I-scanning of the lesion was positive, and a biopsy result compatible with metastatic follicular carcinoma prompted local radiation therapy (5500 rads). In June 1975 an opacity in the left lung was noted on chest $x$-ray to be consistent with another metastatic thyroid lesion, and the patient was treated with

Address for reprints: John S. Kennerdell, MD, Eye and Ear Hospital of Pittsburgh, 230 Lothrop Street, Pittsburgh, Pennsylvania 15213, USA

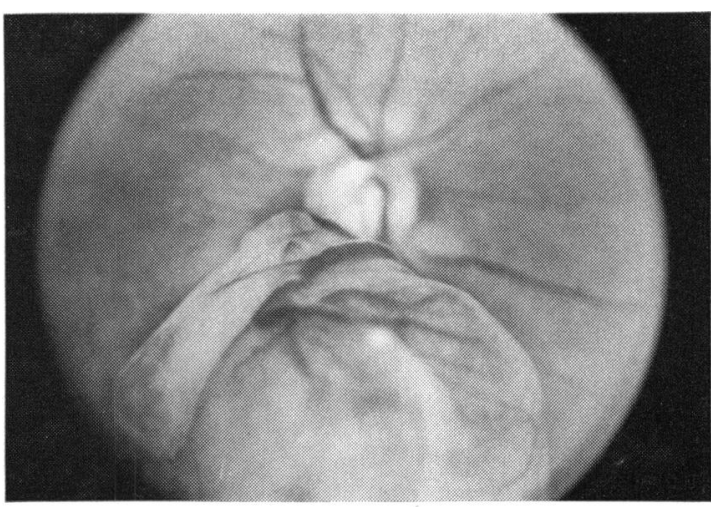

Fig. 1 Large solid lesion in the right fundus, extending into the vitreous

doxorubicin hydrochloride (Adriamycin) $80 \mathrm{mg} / \mathrm{m}^{2}$ for 3 weeks.

The patient was first seen at our eye clinic in August 1976 with the chief complaint of dyschromatopsia of the right eye. Past eye history was negative except for a brief bout of bilateral iritis that had resolved in 1973 after treatment with topical steroids and atropine.

In August 1976 the best corrected vision was found to be 20/60 in the right eye and 20/30 in the left eye. The extraocular movements and pupillary reactions were normal. There was no exophthalmos, and nothing abnormal was found on palpating the orbit. Examination of the lids, lashes, conjunctiva, and sclera showed nothing abnormal. Crenated keratic precipitates of both corneas were noted, but the anterior chamber, iris, and lens in both eyes were normal.

Funduscopy of the right eye revealed a large, pink lesion of solid appearance extending from the inferior border of the disc to the inferior equatorial region (Fig.1). Funduscopy of the left eye was unremarkable. 


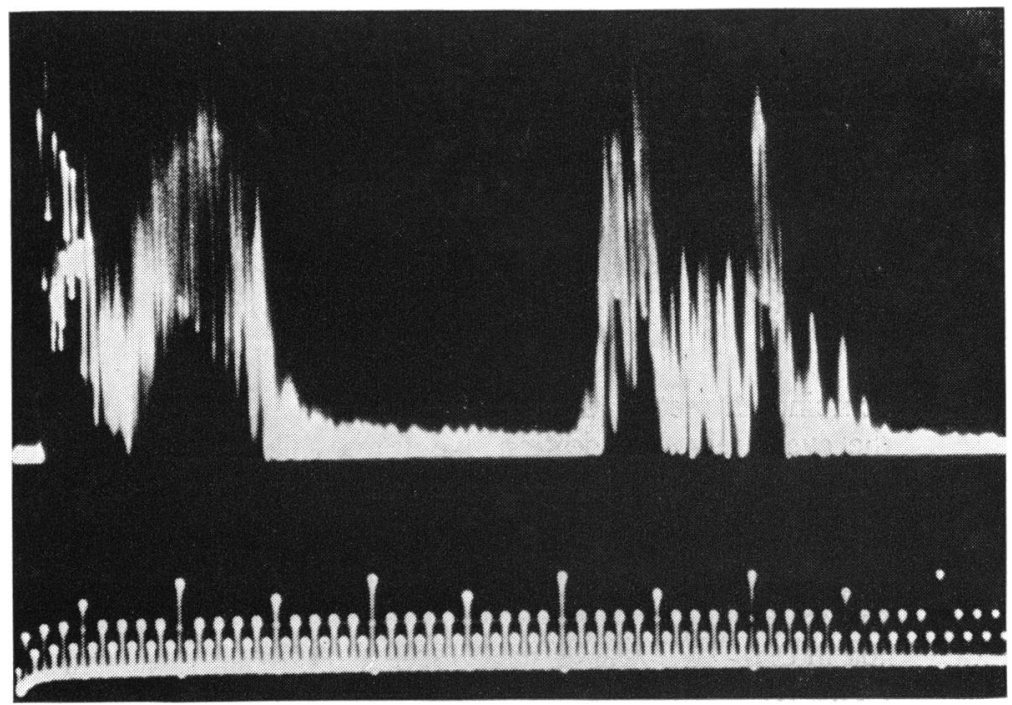

Fig. 2 A-scan of right eye showing a solid, posterior lesion of approximately $9 \mathrm{~mm}$ height

Fig. 3 B-scan of right eye showing a round, elevated, solid, posterior intraocular lesion

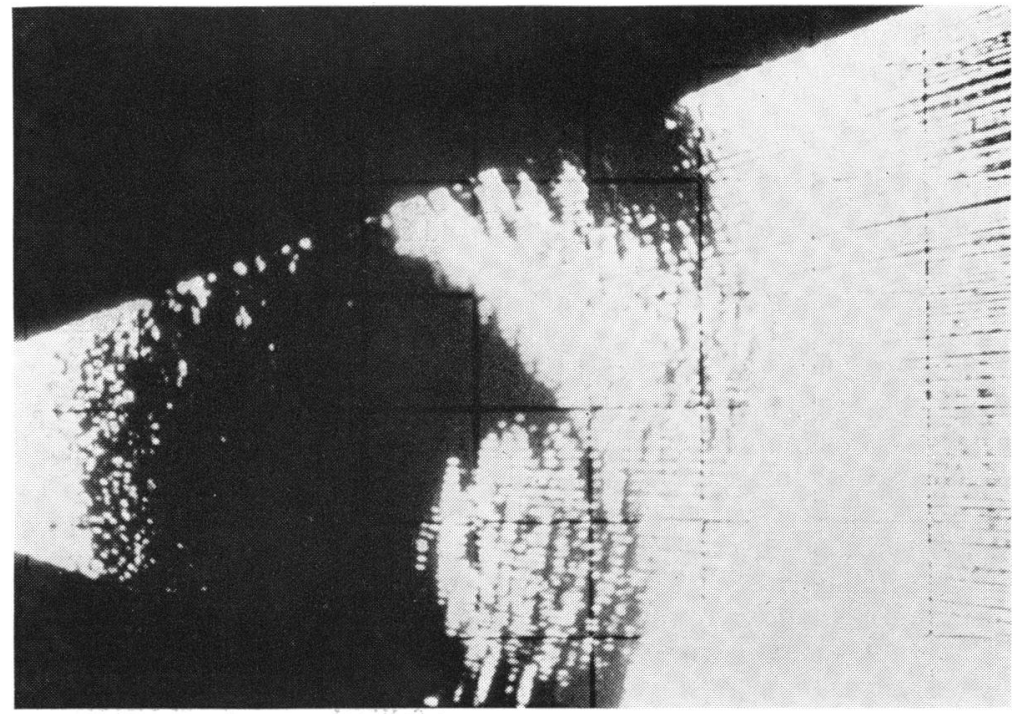

Examination of the visual field of the right eye showed a depression of the superior field with steep borders extending to include fixation. A- and B-scan of the right eye and orbit (Figs. 2 and 3) were compatible with a solid, elevated posterior pole lesion involving the posterior wall of the globe but not the orbit. Fluorescein angiography of the same lesion (Fig. 4) showed 2 contiguous choroidal lesions that leaked fluorescein profusely. An ${ }^{131}$ I-scan of both orbits and of the paratracheal area was performed and was negative. The patient, however, had inadvertently continued to take her L-tri- iodothyronine prior to the scan. After discontinuation of the medication a repeat scan was positive for ${ }^{131}$ I uptake in the right orbital area and, in addition, in 3 distinct areas in the thyroid bed (Fig. 5).

The patient's vision in the right eye over the following week was reduced to hand motion secondary to a spontaneous vitreous haemorrhage. She was treated with 4985 rads from a cobalt-60 unit to the right orbital and periorbital area through a single right lateral port. Over the following 6 months there was a clearing of the vitreous haemorrhage, but the patient developed a total retinal detachment. 


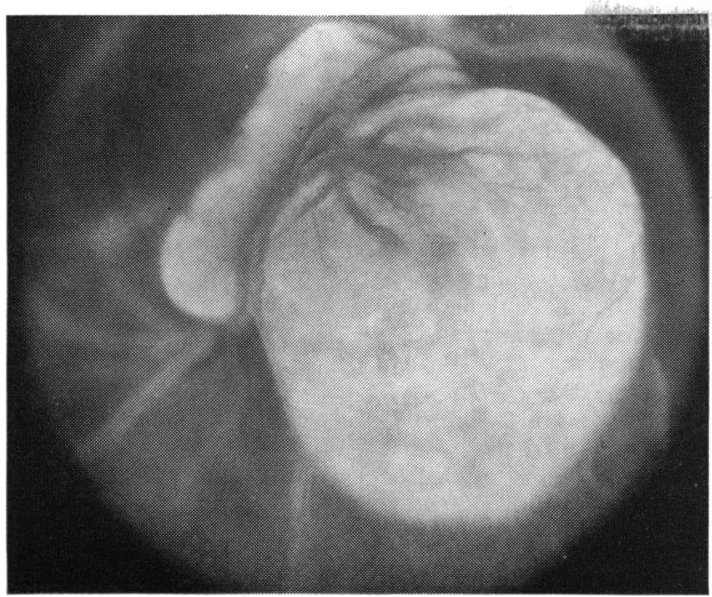

Fig. 4 Fluorescein angiogram of right eye showing heavy fluorescein concentration in the lesion

There was no evidence of progression or regression of the tumour. The visual acuity in the right eye 12 months after radiation therapy was light perception.

\section{Discussion}

The orbit and globe are not in the list of common sites to which systemic carcinoma metastasises. Reports of incidence vary. Hart (1962) and Rose (1965) point out that metastases to the globe and orbit are relatively infrequent. A survey (Albert et al., 1967) of 213 patients with primary tumours disclosed 10 patients who had eye or orbital metastases-an incidence of $4.7 \%$, which the authors thought suggested more frequent metastasis than previously shown. Bloch and Gartner (1971) studied 230 patients with known systemic carcinoma regardless of clinical evidence of orbital or ocular involvement and found 28 eyes with eye/orbital metastases-a $12 \%$ incidence. There is general agreement that among primary malignancies the ones most commonly found to metastasise to the eye or orbit are from the breast and lung (Hart, 1962; Jensen, 1970; Bloch and Gartner, 1971; Font and Ferry, 1976). Other less frequent primaries found to do so are in the kidneys, testicles, prostate, and bowel (Hart, 1962; Jensen, 1970; Bloch and Gartner, 1971; Ferry and Font, 1974, 1975; Font and Ferry, 1976). In our survey we specifically looked for reports of ocular metastasis from the thyroid.

Evaluation of orbital and ocular metastases can be approached in several ways. The authors in 2 surveys (Albert et al., 1967; Bloch and Gartner, 1971) looked at metastases of systemic carcinomas. In combining their data we found among 443 cases 9 to be primary thyroid tumours; of these only 1 case was found to have ocular/orbital metastasis (it was unclear whether to the globe or orbit).

Two studies surveyed the sites to which primary carcinomas of the thyroid metastasise. Heitz et al. (1976) studied 573 primary malignant thyroid tumours and list none as metastatic to the eye or orbit. Frazell and Duffy (1951) studied 40 cases of Hürthle cell cancer of the thyroid and found 1 of these to be metastatic to the eye, but it was unclear whether to the eye or orbit.

In evaluating eye and orbital metastases Hart (1962), among 133 cases from the Armed Forces Institute of Pathology, found 1 to be of thyroid origin with metastasis to the uvea. Ferry and Font (1974) several years later analysed 227 Armed Forces Institute of Pathology cases and again listed 1 case of thyroid carcinoma metastasising to the uvea.
Fig. $5 \quad{ }^{131}$ I scan interpreted as showing significant uptake of ${ }^{131} I$ in the right orbit and in the thyroid bed

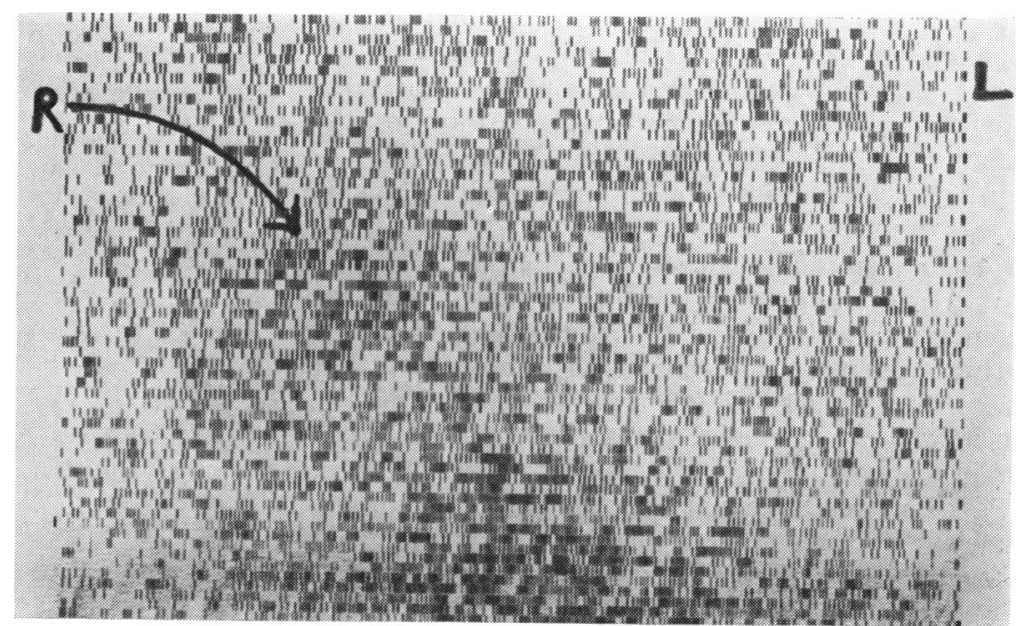


Presumably this case is the same one alluded to 9 years earlier by Hart.

Among 51 orbital tumours Rose (1965) found 5 to be metastatic from the thyroid. In every instance the thyroid metastases were to the extraocular muscles.

In addition to the larger series already mentioned we found 4 other reports (Knapp, 1923; Appalanarsayya and Satyrendran, 1964; Oberman et al., 1969; Dhoine et al., 1973), each one dealing with 1 case of thyroid metastasis. In each instance the metastasis involved the orbit.

Finally, 2 standard textbooks (Henderson, 1973; Reese, 1976) mention thyroid metastases to the eye. Henderson (1973) describes 2 cases of thyroid carcinoma both with metastases to the orbit. Reese (1976) alludes to thyroid metastasis to the eye under subheadings of uveal, eyelid, and orbital metastases. He shows fundus pictures of the posterior pole of a case of metastatic thyroid carcinoma to the choroid of both eyes.

In short, in addition to our present report our review reveals a total of 15 primary thyroid carcinomas metastatic to the eye or orbit. In 2 cases the exact location is not specified clearly. It is noteworthy that 11 of the 15 cases are definitely orbital metastases and only 2 are definitely ocular. The reason for such a propensity is unclear. It is known that both follicular and papillary carcinoma of the thyroid can spread to lymph nodes (Williams, 1974). Duke-Elder and Wybar (1961) state: 'In the orbit there are no lymphatic nodes and no lymphatic vessels have been demonstrated.... Probably the main lymph drainage from the orbit accompanies the veins through the inferior orbital fissure to the internal maxillary nodes; thence to the superior deep cervical nodes.' A study using radioisotope thyroidolymphography and orbitolymphography (Kriss, 1970) suggests a probable lymphatic channel connection between the thyroid gland and the orbit. Konishi et al. (1974) consider that such thyroido-orbital lymphatic channel anastomoses may be the route for orbital deposition of thyroglobulinantithyroglobulin immune complexes with Graves's ophthalmopathy.

The apparent predisposition of thyroid carcinoma to orbital rather than ocular spread could be compatible with Kriss's (1970) proposed thyroidoorbital pathway, but may well occur on a still unexplained basis. It is, nevertheless, interesting that in animal experiments (Albert et al., 1967) as well as in clinicopathologic studies (Bloch and Gartner, 1971; Ferry and Font, 1974) it appears that tumours in general seem to metastasise to the eye itself in most instances. In our review it seems that with thyroid carcinoma the pattern is reversed: thyroid carcinoma metastases to the orbit are commoner than to the globe.

\section{References}

Albert, D. M., Rubenstein, R. A., and Scheie, H. G. (1967). Tumor metastasis to the eye. Part I. Incidence in 213 adult patients with generalized malignancy. American Journal of Ophthalmology, 63, 723-732.

Albert, D. M., Zimmermann, A. W., and Zeidman, I. (1967). Tumor metastasis to the eye. Part III. The fate of circulating tumor cells to the eye. American Journal of Ophthalmology, 63, 733-738.

Appalanarsayya, K., and Satyrendran, O. M. (1964). Metastases in the lid and orbit from thyroid carcinoma. Orient Archives of Ophthalmology, 2, 183-184.

Bloch, R. S., and Gartner, S. (1971). The incidence of ocular metastatic carcinoma. Archives of Ophthalmology, 85, 673-675.

Dhoine, G., Woillez, M., and Beal, F. (1973). Metastases thyroidienne orbitaire, guérison après 10 ans. Bulletin des Sociétés d'Ophtalmologie de France, 73, 1229-1231.

Duke-Elder, W. S., and Wybar, K. C. (1961). The Anatomy of the Visual System, vol. 2, p. 479. Mosby: St. Louis, Missouri.

Ferry, A. P., and Font, R. L. (1974). Carcinoma metastatic to the eye and orbit. I. A clinicopathologic study of 227 cases. Archives of Ophthalmology, 92, 276-286.

Ferry, A. P., and Font, R. L. (1975). Carcinoma metastatic to the eye and orbit. II. A clinicopathologic study of 26 patients with carcinoma metastatic to the anterior segment of the eye. Archives of Ophthalmology, 93, 472-482.

Font, R. L., and Ferry, A. P. (1976). Carcinoma metastatic to the eye and orbit. III. A clinicopathologic study of 28 cases metastatic to the orbit. Cancer, 38, 1326-1335.

Frazell, E. L., and Duffy, B. J. (1951). Hürthle-cell cancer of the thyroid. A review of 40 cases. Cancer, 4, 952-956.

Hart, W. M. (1962). Metastatic carcinoma of the eye and orbit. International Ophthalmology Clinics, 2, 465-482.

Heitz, P., Moser, H., and Staub, J. (1976). Thyroid cancer. A study of 573 thyroid tumors and 161 autopsy cases observed over a thirty-year period. Cancer, 37, 23292337.

Henderson, J. W. (1973). Orbital Tumors, pp. 490-494. Saunders: Philadelphia.

Jensen, O. A. (1970). Metastatic tumours of the eye and orbit. A histopathological analysis of a Danish series. Acta Pathologica et Microbiologica Scandinavica, Supplement 212, pp. 201-214.

Knapp, A. (1923). Metastastic thyroid tumor in the orbit. Archives of Ophthalmology, 52, 68-74.

Konishi, J., Herman, M. M., and Kriss, J. P. (1974). Binding of thyrogobulin and thyroglobulin-antithyroglobulin immune complex to extraocular muscle membrane. Endocrinology, 95, 434-446.

Kriss, J. P. (1970). Radioisotopic thyroidolymphography in patients with Graves' disease. Journal of Clinical Endocrinology and Metabolism, 31, 315-324.

Oberman, H. A., Fayos, J. V., and Lampe, I. (1969). Pathology-radiation therapy conference-unusual orbital tumors. University of Michigan Medical Center Journal, 35, 36-38.

Reese, A. B. (1976). Tumors of the Eye, 3rd edn., p. 34 and pp. 421-430. Harper \& Row: Hagerstown.

Rose, A. M. (1965). Die Orbita als Absiedlungsort von Malignomen. Klinische Monatsblätter für Augenheilkunde, 147, 857-862.

Williams, R. H., ed. (1974). Textbook of Endocrinology, 5th edn., pp. 217-218. Saunders: Philadelphia. 